\section{Efeito da adição do resíduo de rocha ornamental nas propriedades e microestrutura de porcelana elétrica aluminosa}

\author{
Effect of the addition of ornamental rock waste on \\ the properties and microstructure of aluminous electrical porcelain
}

Silva, M. A., Paes Jr, H. R., Holanda, J. N. F

Universidade Estadual do Norte Fluminense,

Grupo de Materiais Cerâmicos, Av. Alberto Lamego 2000, 28013-602 - Campos dos Goytacazes - RJ.

e-mail: myrianketos@hotmail.com; herval@uenf.br ; holanda@uenf.br

\section{RESUMO}

As porcelanas aluminosas são utilizadas como materiais de isoladores elétricos de alta tensão. Este tipo de porcelana se caracteriza por apresentar excelentes propriedades físicas, mecânicas e elétricas. As porcelanas aluminosas são fabricadas usando-se formulação de massa do tipo composta contendo caulim, argila plástica, feldspato e alumina. Na literatura é encontrada uma larga faixa de composições para essas porcelanas. Por outro lado, o setor de rochas ornamentais gera enormes quantidades de resíduos sólidos ricos em compostos fundentes, que podem ser usados como matéria-prima alternativa na fabricação de porcelanas. Neste trabalho foi estudada porcelana elétrica aluminosa incorporada com até $35 \%$ em peso de resíduo de rocha ornamental em substituição do feldspato sódico, que é uma matéria-prima natural. As massas cerâmicas foram preparadas pelo processo via seca. Peças de porcelanas aluminosa em forma de disco foram preparadas por prensagem uniaxial a $50 \mathrm{MPa}$. As amostras foram sinterizadas em forno tubular a $1350{ }^{\circ} \mathrm{C}$ por $1 \mathrm{~h}$. As seguintes propriedades tecnológicas foram avaliadas: retração linear, absorção de água, massa específica aparente, porosidade aparente, resistência à compressão e resistividade elétrica. A microestrutura sinterizada foi acompanhada por microscopia eletrônica de varredura e difração de raios X. Os resultados experimentais mostram que o resíduo de rocha ornamental pode substituir em até $10 \%$ em peso o feldspato sódico na formulação de porcelana aluminosa. A microestrutura sinterizada foi fortemente influenciada pela adição do resíduo de rocha ornamental.

Palavras-chave: Resíduo de rocha ornamental, porcelana aluminosa, propriedades, microestrutura.

\section{ABSTRACT}

Aluminous porcelains are used as materials for high voltage electrical insulation. This type of porcelain is characterized by their excellent physical, mechanical and electrical properties. Aluminous porcelains are manufactured using compound body formulation containing kaolin, plastic clay, feldspar and alumina. A wide range of compositions is found in the literature for these porcelains. On the other hand, the ornamental rock sector generates huge amounts of solid wastes rich in flux materials, which can be used as an alternative raw material in the manufacture of porcelains. The present work studied aluminous electrical porcelain with up to $35 \mathrm{wt} . \%$ of ornamental rock waste in replacement of sodium feldspar, which is a natural raw material. The ceramic pastes were prepared by the dry process. Pieces of disc-shaped aluminous porcelain were prepared by uniaxial pressing with $50 \mathrm{MPa}$. The samples were sintered in a tubular furnace at $1350{ }^{\circ} \mathrm{C}$ for $1 \mathrm{~h}$. The following technological properties were evaluated: linear shrinkage, water absorption, bulk density, apparent porosity, compressive strength and electrical resistivity. The sintered microstructure was analyzed 
by scanning electron microscopy and X-ray diffraction. Experimental results show that ornamental rock waste can replace up to $10 \%$ of sodium feldspar in the formulation of aluminous porcelain. The sintered microstructure was strongly influenced by the addition of ornamental rock waste.

Keywords: Ornamental rock waste, aluminous porcelains, properties, microstructure

\section{INTRODUÇÃO}

Porcelana é um produto impermeável e translúcido que se distingue de outros produtos cerâmicos, especialmente por sua vitrificação, transparência e resistência mecânica. A porcelana é usada em casas, laboratórios e aplicações industriais. Para uso técnico a porcelana é designada como produtos elétricos, químicos, mecânicos, mercadorias estruturais e térmicas [1].

As porcelanas são produzidas a partir da mistura de matérias-primas naturais compostas de argila, quartzo, caulim e feldspatos [2]. A argila dá a plasticidade necessária para a conformação da mistura cerâmica, o quartzo mantém a estrutura que é formada durante a queima e o feldspato serve como fundente formador de fase líquida [3].

As porcelanas triaxiais formadas por alumina, feldspato e caulim são denominadas de porcelanas aluminosas. Nestas porcelanas, contudo, o quartzo é substituído por alumina. Este tipo de porcelana é utilizado na fabricação de isoladores elétricos de alta tensão [2], por possuírem propriedades dielétricas adequadas e propriedade mecânica superiores as porcelanas que utilizam o quartzo.

O Brasil é um dos maiores produtores e exportadores de rochas ornamentais do mundo. Dentre elas, destaca-se o mármore, o granito propriamente dito, o diorito, e o gnaisse, comercialmente conhecidos por mármore e granito. No processo de extração, os blocos são levados à serraria onde é gerado um resíduo na forma de lama abrasiva. Esta lama é geralmente depositada num pátio, porém a quantidade produzida é significativa. Após secagem, a lama transforma-se em um pó fino não biodegradável. Com isso a indústria de rochas ornamentais gera grandes quantidades de resíduos que terão de ser descartados. Estes resíduos são atrativos para o aproveitamento cerâmico por serem constituídos de $\mathrm{SiO}_{2}, \mathrm{Al}_{2} \mathrm{O}_{3}, \mathrm{~K}_{2} \mathrm{O}, \mathrm{Na}_{2} \mathrm{O}$ e $\mathrm{CaO}$ [4-7]. Estes compostos são normalmente encontrados nas matérias-primas usadas na fabricação de produtos cerâmicos.

A área de cerâmica pode ser a solução tecnológica mais adequada para valorização e inertização definitiva de resíduo sólido de rocha ornamental, sem causar qualquer outro tipo de poluição. Destaca-se ainda que a incorporação de resíduos de rochas ornamentais em massas cerâmicas, além de contribuir para a solução do problema ambiental, pode também contribuir para a redução do custo de energia do processo produtivo [8]. Por outro lado, os materiais fundentes naturais mais utilizados na fabricação de porcelanas são os feldspatos potássico e sódico [9-11]. Assim, o resíduo de rocha ornamental rico em óxidos fundentes é atraente para ser incorporado em produtos de porcelana elétrica [12].

Neste trabalho foi usado um resíduo de rocha ornamental em substituição do feldspato sódico na formulação de uma massa cerâmica para fabricação de porcelana elétrica aluminosa. Ressalta-se a importância do reuso do resíduo de rocha ornamental em virtude da crescente conscientização ambiental da sociedade moderna.

\section{MATERIAIS E MÉTODOS}

Neste trabalho foram utilizadas as seguintes matérias-primas: caulim, argila plástica, feldspato sódico, alumina- $\alpha$ e resíduo de rocha ornamental. O caulim, feldspato sódico e alumina são matérias-primas comerciais. A argila plástica é proveniente da região de Campos dos Goytacazes-RJ. O resíduo de rocha ornamental, que daqui por diante será denominado de RRO, é proveniente do processo de serragem e beneficiamento de rochas ornamentais na região de Santo Antônio de Pádua-RJ. 
A composição química do resíduo de rocha ornamental foi determinada via espectrometria de energia dispersiva de raios X. A composição química da argila plástica foi determinada via fluorescência de raios X. As composições químicas do caulim, feldspato sódico e alumina foram fornecidas pelos fabricantes. A perda ao fogo do resíduo de rocha ornamental e argila plástica foi determinada de acordo com a seguinte expressão $\mathrm{PF}=\mathrm{Ms}-\mathrm{Mc} / \mathrm{Ms}$ x 100, onde Ms é a massa da amostra seca a $110^{\circ} \mathrm{C}$ e Mc é a massa da amostra calcinada a $1000^{\circ} \mathrm{C}$ durante $1 \mathrm{~h}$.

A Tabela 1 apresenta as composições das formulações estudadas neste trabalho. As massas cerâmicas foram formuladas a partir da substituição gradual do feldspato sódico por resíduo de rocha ornamental. As matérias-primas foram moídas a seco e misturadas em um moinho de bolas de laboratório. Em seguida as matérias-primas foram passadas em peneira de malha de 325 mesh (ABNT 45 um). As massas cerâmicas foram misturadas, homogeneizadas e granuladas através do processo via seca. O teor de umidade (massa de umidade/massa seca) foi ajustado para $7 \%$.

Tabela 1: Composição das massas cerâmicas (\% em peso).

\begin{tabular}{c|c|c|c|c|c}
\hline $\begin{array}{c}\text { MASSA } \\
\text { CERÂMICA }\end{array}$ & CAULIM & ARGILA PLÁSTICA & ALUMINA & $\begin{array}{c}\text { FELDSPATO } \\
\text { SÓDICO }\end{array}$ & RRO \\
\hline A & 20 & 25 & 20 & 35 & 0 \\
\hline B & 20 & 25 & 20 & 25 & 10 \\
\hline C & 20 & 25 & 20 & 15 & 20 \\
\hline D & 20 & 25 & 20 & 5 & 30 \\
\hline E & 20 & 25 & 20 & 0 & 35 \\
\hline
\end{tabular}

A preparação das peças de porcelana aluminosa foi feita por prensagem uniaxial a $50 \mathrm{MPa}$, utilizandose uma matriz de aço com cavidade cilíndrica $(\varphi=16 \mathrm{~mm})$. Em seguida as peças foram secadas em estufa a $110 \mathrm{oC}$ durante $24 \mathrm{~h}$. As peças secas foram sinterizadas na temperatura de $1350{ }^{\circ} \mathrm{C}$ durante $1 \mathrm{~h}$.

As seguintes propriedades tecnológicas foram determinadas: retração linear, absorção de água, massa específica aparente, porosidade aparente, resistência á tração pelo método de compressão diametral e resistividade elétrica. A microestrutura da superfície de fratura das peças sinterizadas foi observada por microscopia eletrônica de varredura (MEV marca Shimadzu, modelo SSX-550), utilizando-se uma voltagem de aceleração de elétrons de $15 \mathrm{kV}$. Análise mineralógica qualitativa das peças sinterizadas foi feita por difração de raios-X (Difratômetro marca Shimadzu, modelo XRD-7000), utilizando-se radiação $\mathrm{Cu}-\mathrm{K} \alpha$.

\section{RESULTADOS E DISCUSSÃO}

As composições químicas das matérias-primas são apresentadas na Tabela 2. O resíduo de rocha ornamental é constituído principalmente de $\mathrm{SiO} 2$ e $\mathrm{Al} 2 \mathrm{O} 3$, mas contém também uma quantidade apreciável de óxidos fundentes $\left(\sum \mathrm{K}_{2} \mathrm{O}+\mathrm{Na}_{2} \mathrm{O}+\mathrm{Fe}_{2} \mathrm{O}_{3}+\mathrm{CaO}+\mathrm{MgO}\right)$. Quando comparado ao feldspato sódico, observa-se que o resíduo de rocha ornamental contém uma quantidade de óxidos fundentes $(14,75 \%$ em peso) superior aquela do feldspato sódico $(11,50 \%$ em peso). Isto significa que o resíduo de rocha ornamental utilizado neste trabalho é altamente atrativo para substituir o material fundente natural (feldspato sódico) na formulação da massa cerâmica para porcelana elétrica aluminosa. A argila plástica usada apresenta composição química típica esperada, sendo rica em $\mathrm{SiO}_{2}, \mathrm{Al}_{2} \mathrm{O}_{3}$ e $\mathrm{Fe}_{2} \mathrm{O}_{3}$ com quantidades menores de óxidos de Ti, $\mathrm{Ca}, \mathrm{K}$ e $\mathrm{Mn}$. O caulim e alumina apresentam alta pureza e são adequados para uso na fabricação de porcelana elétrica.

Na Figura 1 são apresentados os valores de retração linear das peças cerâmicas incorporadas com até $35 \%$ em peso de resíduo de rocha ornamental sinterizadas a $1350{ }^{\circ} \mathrm{C}$. Pode-se observar que a retração linear das peças cerâmicas é influenciada pela adição do resíduo. Em geral as peças cerâmicas contendo maior 
quantidade de resíduo apresentaram menor retração linear. Isto é um efeito positivo, pois contribui para uma melhor estabilidade dimensional das peças de porcelana elétrica. A razão para isto está relacionada à presença de quartzo livre no resíduo de resíduo de rocha ornamental. Os valores de retração linear obtidos na faixa de 10,96 -11,49 \% estão dentro da faixa para produção industrial de porcelanas elétricas.

Tabela 2: Composição química (\% em peso) das matérias-primas.

\begin{tabular}{l|l|l|l|l|l|l|l|l|l|l}
\hline MATÉRIAS PRIMAS & $\mathrm{SiO}_{2}$ & $\mathrm{Al}_{2} \mathrm{O}_{3}$ & $\mathrm{Fe}_{2} \mathrm{O}_{3}$ & $\mathrm{TiO}_{2}$ & $\mathbf{C a O}$ & $\mathrm{MgO}$ & $\mathrm{K}_{\mathbf{2}} \mathbf{O}$ & $\mathbf{N a}_{2} \mathbf{O}$ & $\mathrm{MnO}$ & P.F \\
\hline Caulim & 49,7 & 33,74 & 0,22 & $<0,01$ & 0,30 & 0,061 & 1,97 & 0,52 & - & 14,01 \\
\hline Alumina & 0,027 & 99,7 & 0,022 & - & - & - & - & 0,12 & & 0,05 \\
\hline Albita & 69,55 & 18,82 & 0,14 & 0,017 & 0,17 & 0,09 & 1,47 & 9,63 & - & 0,32 \\
\hline Resíduo & 66,43 & 17,26 & 3,70 & 0,83 & 2,23 & 0,32 & 7,49 & 1,01 & 0,08 & 0,65 \\
\hline Argila & 46,74 & 36,09 & 9,68 & 1,71 & 0,50 & - & 2,94 & & 0,07 & 10,95 \\
\hline
\end{tabular}

$\mathrm{PF}=$ perda de fogo

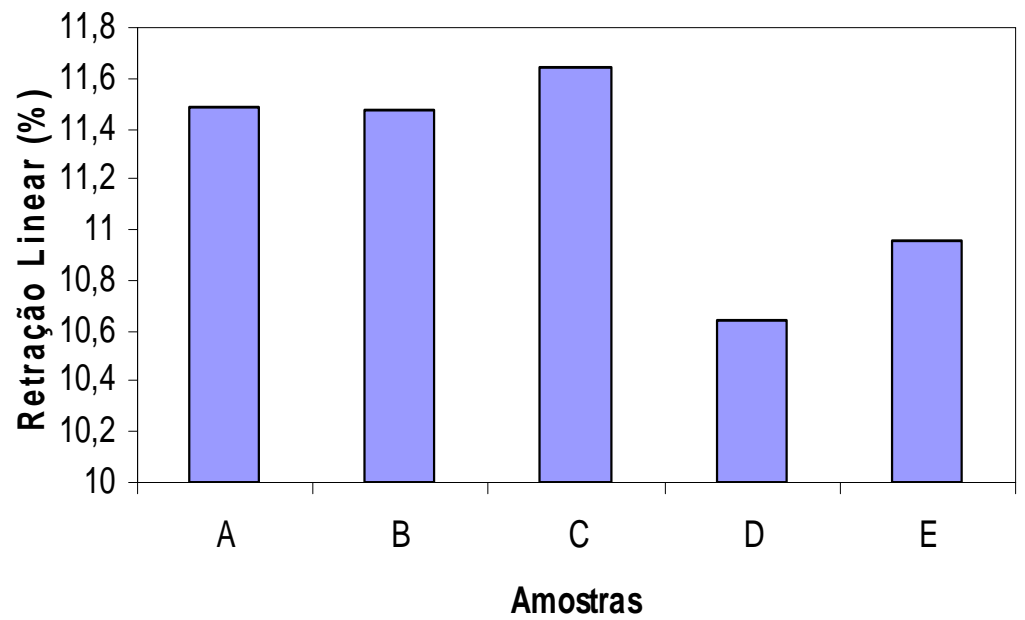

Figura 1: Retração linear das amostras com até $35 \%$ em peso de RRO.

Na Figura 2 são apresentados os valores de absorção de água das peças cerâmicas sinterizadas. Os resultados mostram que os valores de absorção de água das peças cerâmicas são fortemente influenciados pela adição do resíduo de rocha ornamental. Neste caso se observa um aumento da absorção de água para adições de resíduo acima de $10 \%$ em peso. Isto é interessante pelo fato de que na temperatura de $1350{ }^{\circ} \mathrm{C}$ as massas cerâmicas A (isenta de resíduo) e B (10 \% em peso de resíduo) apresentam valores de absorção de água praticamente nulos $(\sim 0,003 \%)$. Em seguida mais adição de resíduo implica num aumento da absorção de água. Por outro lado, a absorção de água é uma propriedade física usada em normas técnicas para especificar produtos cerâmicos para aplicações diversas. Em particular as porcelanas elétricas devem apresentar um valor de absorção de água (AA) $\leq 0,5 \%$. Neste contexto, as peças de porcelanas aluminosas estudadas neste trabalho sinterizadas a $1350^{\circ} \mathrm{C}$ são apropriadas para este tipo de aplicação. Verifica-se que se obtém porcelana elétrica aluminosa de alta qualidade com porosidade aberta na estrutura praticamente nula (AA $\sim 0,0 \%$ ) para adições de até $10 \%$ em peso de resíduo. 


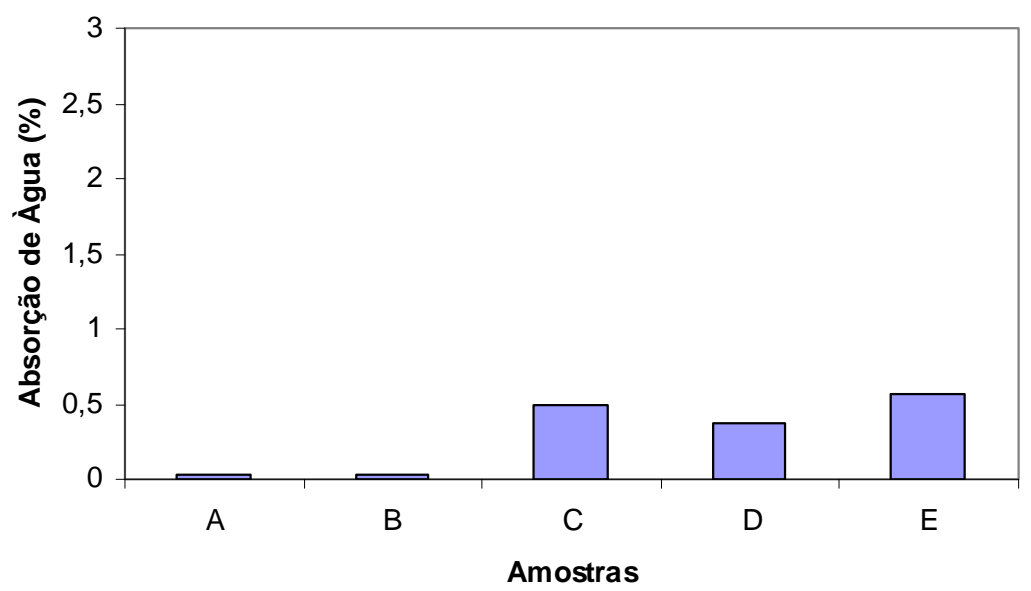

Figura 2: Absorção de água das amostras com até $35 \%$ em peso de RRO.

Na Figura 3 são apresentados os valores de massa específica aparente das peças cerâmicas sinterizadas a $1350{ }^{\circ} \mathrm{C}$. Os resultados mostram que a adição do resíduo influenciou o comportamento de densificação das peças cerâmicas. Para adições de até $20 \%$ em peso de RRO a massa específica aparente das peças cerâmicas permaneceu constante $\left(2,53 \mathrm{~g} / \mathrm{cm}^{3}\right)$. Para adições acima de $20 \%$ em peso a massa específica aparente tende a diminuir. Este efeito se deve fundamentalmente ao inchamento das peças devido à formação de porosidade fechada na estrutura da peça cerâmica. Os valores de massa específica aparente das peças sinterizadas na faixa de $2,46-2,53 \mathrm{~g} / \mathrm{cm}^{3}$ estão dentro da faixa adequada para produção industrial de porcelana elétrica aluminosa.

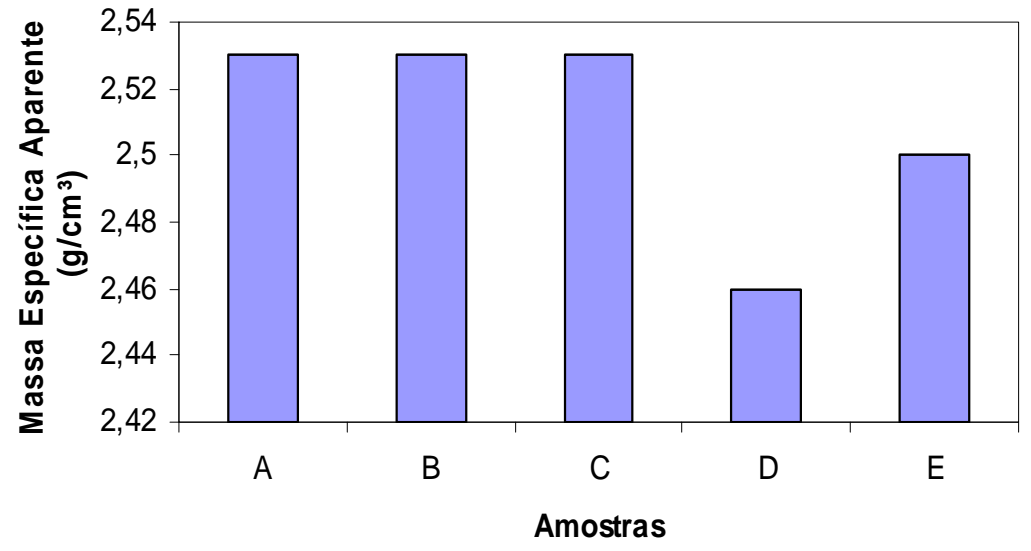

Figura 3: Massa específica aparente das amostras com até $35 \%$ em peso de RRO.

Na Figura 4 são apresentados os valores de porosidade aparente das peças cerâmicas sinterizadas. Verifica-se que foram obtidos baixos valores de porosidade aparente (PA $=1,08-2,38 \%$ ). 


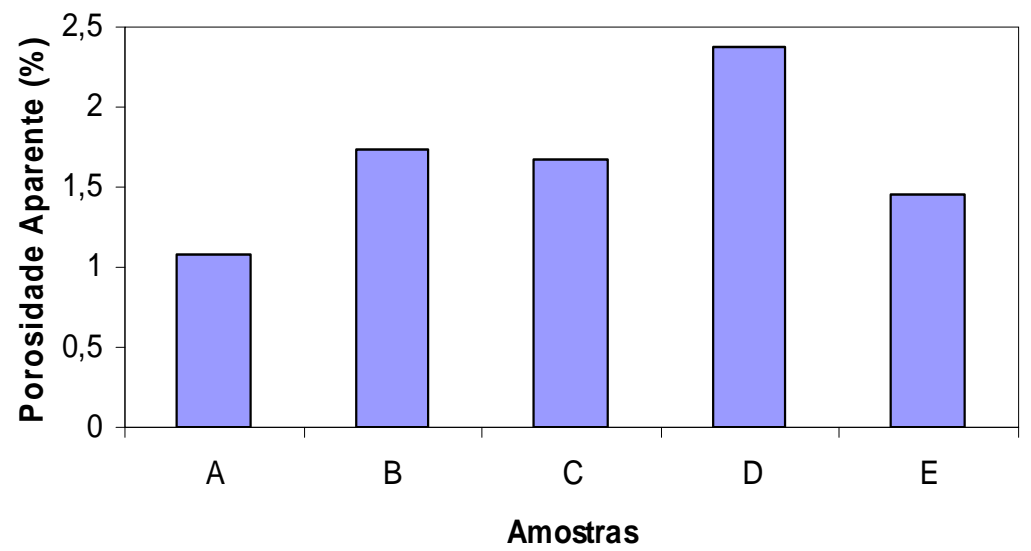

Figura 4: Porosidade aparente das amostras com até $35 \%$ em peso de RRO.

Na Figura 5 são apresentados os valores de resistência à tração pelo método de compressão diametral das peças cerâmicas incorporadas com até $35 \%$ em peso de RRO sinterizadas a $1350{ }^{\circ} \mathrm{C}$. Pode-se observar que, em geral, tem-se um leve aumento dos valores de resistência à tração para as peças contendo resíduo.

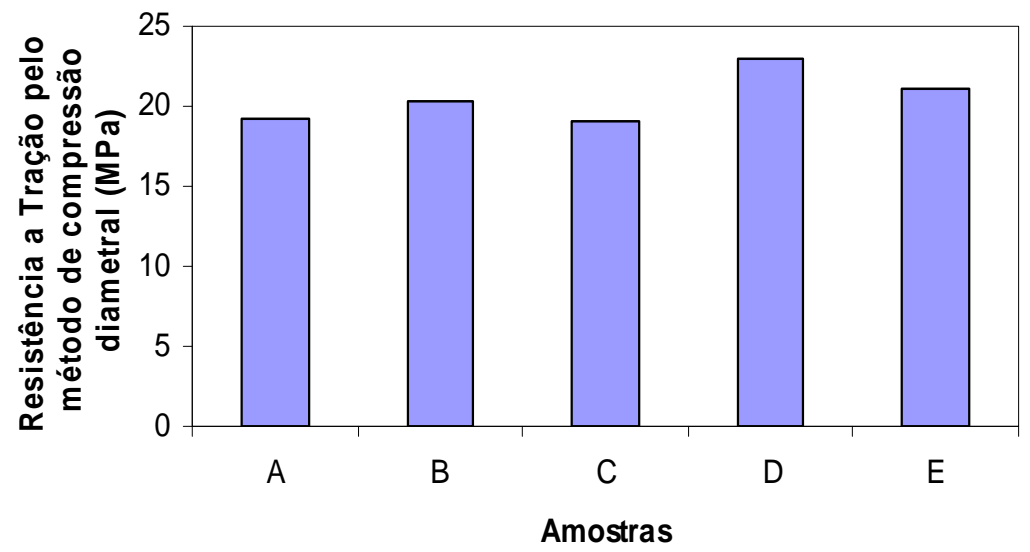

Figura 5: Resistência à tração das amostras com até $35 \%$ em peso de RRO

Na Figura 6 são apresentados os valores de resistividade elétrica de volume das peças cerâmicas sinterizadas. Os resultados mostram que os valores obtidos para resistividade elétrica das peças de porcelana aluminosa preparadas neste trabalho são relativamente altos. Verifica-se, no entanto, que a resistividade elétrica apresentou uma variação complexa com a adição do resíduo de rocha ornamental. A resistividade elétrica atinge um pico em $20 \%$ em peso de resíduo (amostra C). Uma explicação plausível para a ocorrência dessa variação complexa da resistividade elétrica das peças de porcelana elétrica aluminosa estudada está relacionada a fatores como preparação da amostra, blindagem, ruídos de rede e defeitos nas amostras. 


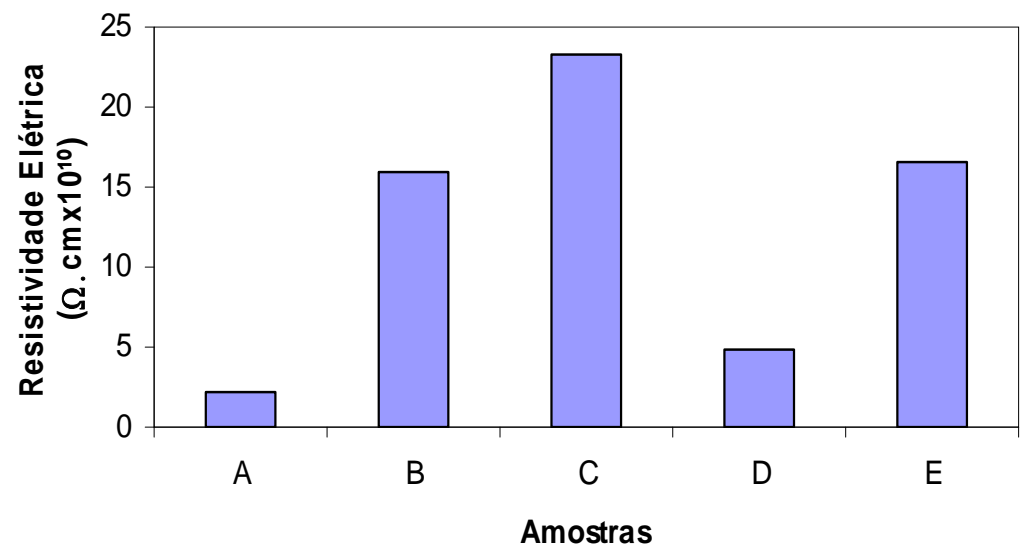

Figura 6: Resistividade elétrica das amostras com até $35 \%$ em peso de RRO.

Nas Figuras 7 (a)-(c) são apresentadas uma série de micrografias obtidas por microscopia eletrônica de varredura via imagens de elétrons secundários das superfícies de fratura das amostras sinterizadas: a) amostra A (massa com $0 \%$ em peso de RRO); b) amostra C (com $20 \%$ em peso de RRO); e c) amostra E (com $35 \%$ em peso de RRO). O efeito da adição do resíduo é visível na estrutura da peça sinterizada, o qual resulta numa estrutura mais rugosa e porosidade fechada. Os poros fechados são tipicamente poros isolados de morfologia esférica ou arredondados na matriz cerâmica vitrificada.

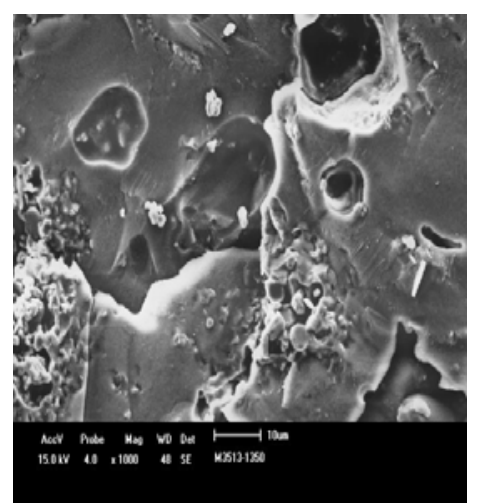

(a)

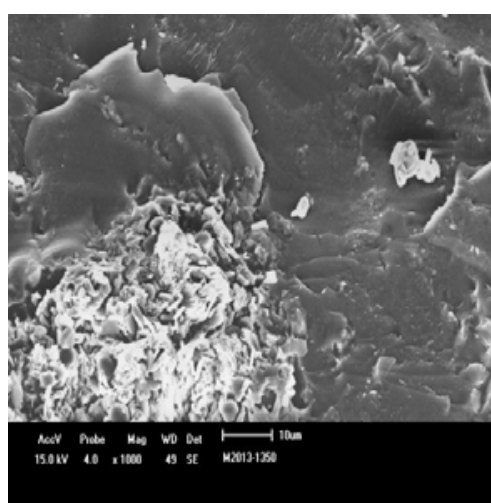

(c)

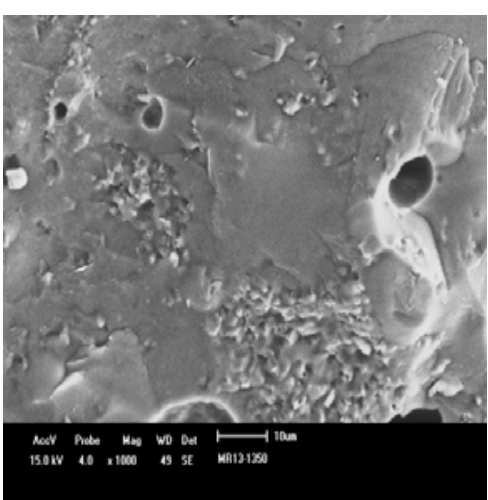

(e)

Figura 7: Micrografias da superfície da fraturada das amostras A, C e E.

Nas Figuras 8-10 são apresentados os difratogramas de raios X para as amostras de porcelana elétrica A (com $0 \%$ em peso de RRO), C (com $20 \%$ em peso de RRO) e E (com $35 \%$ em peso de RRO) sinterizadas a $1350{ }^{\circ} \mathrm{C}$.

As análises mineralógicas qualitativas das peças de porcelana aluminosa sinterizadas indicaram que as fases cristalinas presentes são basicamente as mesmas independentemente da quantidade de RRO incorporado: $\alpha$-alumina, mullita, quartzo. No entanto, as intensidades dos picos de difração das formulações apresentam pequenas diferenças em relação à incorporação do resíduo. 


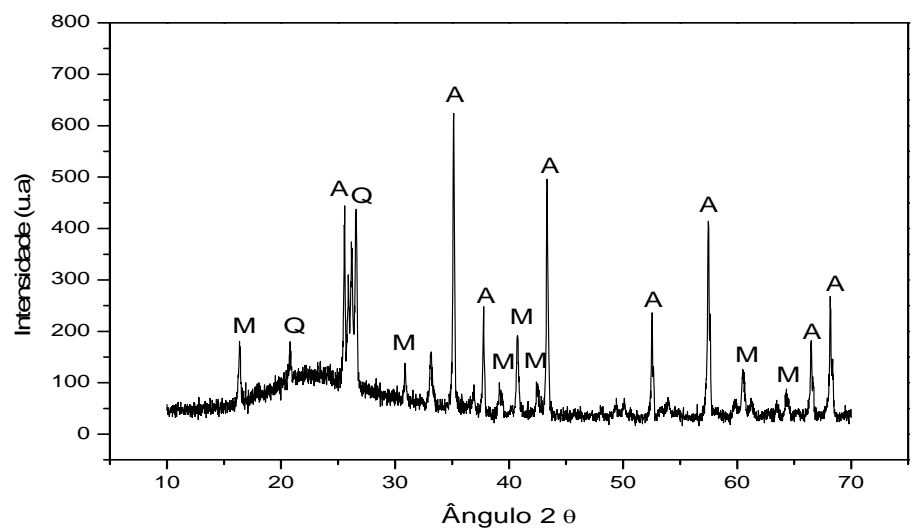

Figura 8: Difratograma de raios $X$ da amostra A: Q - Quartzo; A - $\alpha$ - Alumina; $M$ - Mullita.

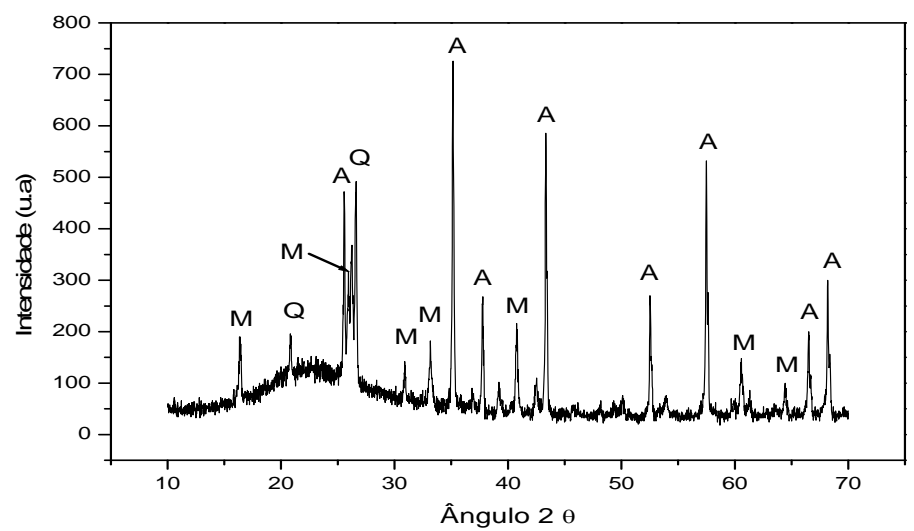

Figura 9: Difratograma de raios $X$ da amostra C: Q - Quartzo; A - $\alpha$ - Alumina; $M$ - Mullita.

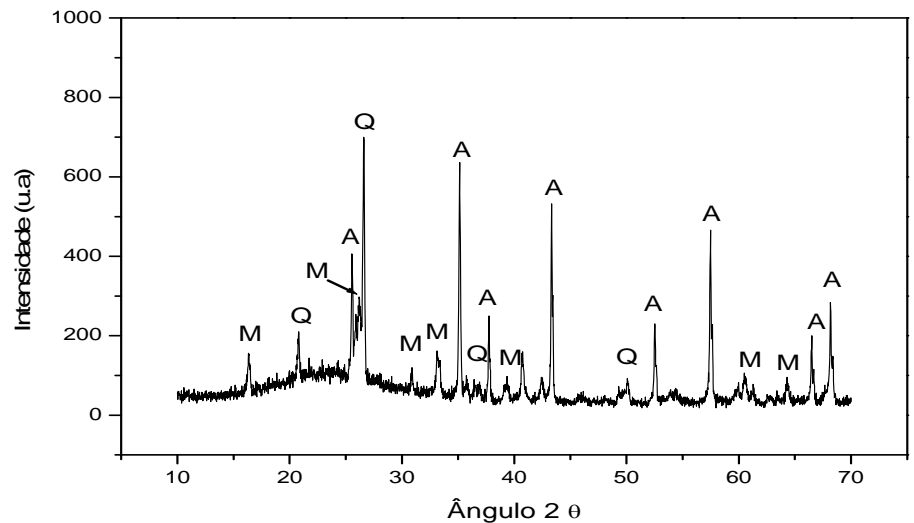

Figura 10: Difratograma de raios X da amostra E: Q - Quartzo; A - $\alpha$ - Alumina; M - Mullita.

\section{CONCLUSÕES}

Os resultados obtidos nos diversos experimentos realizados indicam que o resíduo de rocha ornamental utilizado, proveniente do município de Santo Antônio de Pádua - RJ, apresenta potencial para substituição parcial do feldspato sódico numa massa cerâmica para fabricação de porcelana elétrica aluminosa. 
O aumento gradativo do resíduo na massa cerâmica provocou alterações nas propriedades física e mecânica e também na microestrutura das peças cerâmicas. Os resultados indicam que se pode obter porcelanas aluminosas de alta qualidade (AA $\sim 0,0 \%$ ) para adições de até $10 \%$ em peso do resíduo de rocha ornamental utilizado.

\section{AGRADECIMENTOS}

Os autores deste trabalho agradecem ao CNPq, FAPERJ e CAPES pelo apoio financeiro e, também, a ALCOA pelo fornecimento de alumina.

\section{BIBLIOGRAFIA}

[1] CHINELATTO, A. L., SOUZA, D.P.F. "Porcelanas elétricas aluminosas: Parte I - Revisão da literatura", Cerâmica, v.50, n. 313, pp. 62-68, 2004.

[2] CHINELATTO, A. L., SOUZA, D.P.F. "Porcelanas elétricas aluminosas: Parte II - desenvolvimento da microestrutura e sua influência no módulo de ruptura”, Cerâmica, v. 50, n. 315, pp. 172-184, 2004.

[3] OLUPOT, P.W., "Assessment of Ceramic Raw Materials in Uganda for Electrical Porcelain" Thesis (Licentiate in Material Science), Department of Materials Science and Engineering Royal Institute of Technology (KTH), Stockholm, Sweden (2006).

[4] MOREIRA, J.M.S., MANHÃES, J.P.V.T., HOLANDA, J.N.F. "Processing of red ceramic using ornamental rock powder waste", Journal of Materials Processing Technology, v. 196, n. 1-3, pp. 88-93, 2008.

[5] SOUZA, A.J., PINHEIRO, B.C.A., HOLANDA, J.N.F. "Recycling of gneiss rock waste in the manufacture of vitrified floor tiles", Journal of Environmental Management, v. 91, n. 3, pp. 685-689, 2010.

[6] MAGHRABY, A., ABOU ELMAATY, M.A., KHATER, G.A., et al., "Utilization of grantitoid rocks in Taif area as raw materials in ceramic bodies", Journal of American Science, v. 6, n. 10, pp. 691-701, 2010.

[7] MOURA, W.A., LEITE, M.B. "Estudo da viabilidade da produção de blocos com utilização de resíduo de serragem de rochas ornamentais para alvenaria de vedação", Revista da Escola de Minas, v. 64, n. 2, pp. 147154, 2011.

[8] CARVALHO, M.R.S., CARRISSO, R.C.C., RIBEIRO, R.C.C. "Aplicação de feldspatos extraídos de resíduos de pedreiras de granito nas indústrias de cerâmica e vidro, buscando-se as tecnologias limpas". In: Série Anais da XII Jornada de Iniciação Científica, Centro de Tecnologia Mineral. pp. 1-9, São Paulo - SP, Agosto, 2004.

[9] CHATTERJEE, A., CHITWADGI, S., KULKARNI, M., et al., "Efeito da razão entre feldspatos sódico e potássico no desenvolvimento de fases e microestrutura de porcelanatos queimados", Cerâmica Industrial, v. 6, n. 5, pp. 23-26, 2001.

[10] RIELLA, H.G., FRANJNDLICH, E.U.C., DURAZZO, M. "Caracterização e utilização de fundentes em massa cerâmicas", Cerâmica Industrial, v. 7, n. 3, pp. 33-36, 2002.

[11] DAS, S.K., DANA, K. "Differences in densification behavior of K-feldspar and Na-feldspar containing porcelain bodies", Thermochemica Acta, v. 406, pp. 199-206, 2003.

[12] PINHEIRO, B.C.A., "Análise microestrutural de porcelana tradicional". Dissertação de Mestrado UENF-PPGECM, Campos dos Goytacazes, 2005. 